\title{
LINEZOLID METABOLISM IS CATALYZED BY CYP2J2, CYP4F2 AND CYP1B1
}

\section{R. Scott Obach}

Pfizer Inc.

Groton, CT 06340 
Running Title: Linezolid Metabolism by CYP2J2, CYP4F2, and CYP1B1

Corresponding Author: R. Scott Obach, Pfizer Inc., Groton, CT, USA 06340 r.scott.obach@pfier.com

Number of Words in:

Abstract: 213

Introduction: 510

Discussion: 1046

Number of Tables: 1

Number of Figures: 7

Number of References: 22

Number of Text Pages: 15

Abbreviations: HESI: heated electrospray ionization; HLM: human liver microsomes; HRMS: high resolution mass spectrometry; LKY-047: (S)-8,8-dimethyl-2-oxo-7,8-dihydro-2H,6H-pyrano[3,2g]chromen-7-yl (E)-3-(4-nitrophenyl)acrylate; NADPH: nicotinamide adenine dinucleotide phosphate, reduced form; UHPLC: ultra-high pressure liquid chromatography; UV: ultraviolet 


\section{ABSTRACT}

The oxazolidinone antibacterial linezolid has been in clinical use for over twenty years, yet knowledge of the contributions of specific cytochrome P450 enzymes to the metabolic clearance of this drug were mostly unknown. In this investigation it was revealed that three P450 enzymes that had not been previously explored in linezolid metabolism, CYP2J2, CYP4F1, and CYP1B1, catalyzed the 2-hydroxylation and deethyleneation of the morpholine moiety of linezolid. The intrinsic clearance for linezolid metabolism in pooled human liver microsomes was low at $0.51 \mu \mathrm{L} / \mathrm{min} / \mathrm{mg}$ protein, consistent with its in vivo clearance in humans, and the $\mathrm{K}_{\mathrm{M}}$ was high $(>200 \mu \mathrm{M})$. In recombinant human P450 enzymes, a rank order of intrinsic clearance values for linezolid 2-hydroxylation were CYP2J2>>CYP4F2>CYP2C8>CYP1B1 $\approx$ CYP2D6 $\approx C Y P 3 A 4>C Y P 1 A 1>C Y P 3 A 5$, with nine other P450 enzymes showing no linezolid metabolism The effect of selective inhibitors for these eight P450 enzymes on linezolid metabolism in pooled human liver microsomes was evaluated to provide estimates of the relative fractional contributions of these enzymes to linezolid metabolism. These experiments suggest that CYP2J2 and CYP4F2 contribute about 50\% each to linezolid hepatic metabolism. It is proposed that the oxidative metabolic clearance of linezolid is primarily catalyzed by these two unusual P450 enzymes and that this explains the lack of observation of meaningful effects of common perpetrators of drug interactions on linezolid pharmacokinetics.

\section{SIGNIFICANCE STATEMENT}

Linezolid is an important antibacterial drug, but the enzymes involved in its oxidative metabolism were unknown. In this paper, evidence is shown that supports an important role for two enzymes not frequently associated with the metabolism of drugs: CYP2J2 and CYP4F2. These observations offer insight to understand the results of clinical drug-drug interaction studies conducted on linezolid. 


\section{INTRODUCTION}

Linezolid (Figure 1) is an oxazolidinone antibiotic used for infections caused by several species of bacteria such as vancomycin resistant enterococcus and methicillin resistant staphylococcus, among others. It is frequently used in treatment of skin infections and pneumonia. It is a protein synthesis inhibitor which is different from other antimicrobial protein synthesis inhibitors because it inhibits initiation of synthesis by binding to the 50S ribosomal subunit (reviewed by Hashemian, et al., 2018). Available as both oral and intravenous formulations, it is a valuable agent in the armamentarium used to fight serious bacterial infections.

Despite its successful employment as a clinically useful antibiotic, knowledge of the metabolism and disposition of linezolid has gaps. In a radiolabelled metabolism and excretion study of linezolid, almost half of the dose was excreted as unchanged drug in urine (Slatter, et al., 2001) and with 30\% unchanged drug in urine at steady-state (ZYVOX Product label). The remainder was excreted as metabolites that arose via oxidation of the morpholine ring. However, despite knowledge of the structures of metabolites, the enzymes responsible were largely undetermined. In a report by Wynalda, et al., (2000), several cytochrome P450 enzymes were explored for their capability to convert linezolid to 2hydroxylinezolid (termed metabolite M1 in that report), a first metabolic step on the route to the morpholine oxidized metabolites observed in human excreta. The conclusion from that work was that this oxidation arose via the generation of reactive oxygen species that are generated during the catalytic cycle of P450 enzymes. The recombinant heterologously expressed P450 enzymes evaluated in that investigation included the important drug-metabolizing enzymes CYP1A2, 2C8, 2C9, 2C19, 2D6, 3A4, and $3 \mathrm{~A} 5$, as well as some of the ones less frequently associated in the metabolism of drugs such as CYP1A1, $2 \mathrm{~A} 6,2 \mathrm{~B} 6,2 \mathrm{E} 1$, and $4 \mathrm{~A} 11$. But the evidence did not indicate that any one of these enzymes was 
important in this metabolic reaction. In clinical investigations on the effects of drugs on the pharmacokinetics of linezolid, only two agents have been demonstrated to have an impact. Rifampin, a robust inducer of several drug metabolizing enzymes, was shown to cause decreases in linezolid exposure by about $30 \%$ whether administered by the oral or intravenous route (Egle, et al., 2005; Gandelman, et al., 2011). Clarithromycin coadministration caused a moderate increase in linezolid exposure (Bolhuis, et al., 2013) which could be due to inhibition of CYP3A enzymes or P-glycoprotein transport. However, these studies suggest that CYP3A plays, at best, a minor role in linezolid clearance, and the aforementioned in vitro study showed less than $10 \%$ inhibition of the metabolism of linezolid by the CYP3A inhibitor ketoconazole.

During the course of an investigation of P450 reaction phenotyping methodologies in our laboratories, linezolid was one of the drugs being tested and it was unexpectedly shown that it was metabolized by recombinant heterologously expressed CYP2J2 to a substantially greater degree than any other P450 enzymes. Notably, CYP2J2 was not one of the enzymes evaluated previously (Wynalda, et al., 2000). This triggered a reinvestigation of the metabolism of linezolid, using an expanded panel of P450 enzymes and inhibitors. 


\section{METHODS}

Materials. Linezolid and cyp3cide were from the Pfizer sample bank. LKY-047 was prepared according to the method of Phuc, et al. (2017). 1-(3-chlorophenyl)-3-phenylurea was prepared using the method of Mohd Siddique, et al., (2016). 2-Hydroxylinezolid and desethylenelinezolid were biosynthesized using female rabbit liver microsomes in the approach described by Walker, et al., (2014). Sesamin, NADPH, and $\alpha$-naphthoflavone were from Sigma (St. Louis, MO). Ketoconazole was from Research Biochemicals International (Natick, MA). Montelukast was from Sequoia Research Products (Pangbourne, UK). Quinidine was from Fluka (St. Gallen, Switzerland). Pooled human liver microsomes ( $N=54$, mixed sex) were prepared under contract by Xenotech (Lenexa, KS). Recombinant heterologously expressed human cytochrome P450 enzymes and pooled human intestinal microsomes were from Corning/Gentest (Woburn, MA).

Linezolid Metabolite Profiles in Human Liver Microsomes and Recombinant Heterologously Expressed Cytochrome P450 Enzymes. Linezolid $(40 \mu \mathrm{M})$ was incubated with human liver microsomes $(2.0 \mathrm{mg} / \mathrm{mL})$ or P450 enzymes $(100 \mathrm{pmol} / \mathrm{mL})$ in a volume of $0.2 \mathrm{~mL}$ potassium phosphate buffer $(100 \mathrm{mM}, \mathrm{pH} 7.45)$ containing $\mathrm{MgCl}_{2}(3.3 \mathrm{mM})$ and $\mathrm{NADPH}(1.3 \mathrm{mM})$. Incubations were carried out for $1 \mathrm{hr}$ and terminated with the addition of $\mathrm{CH}_{3} \mathrm{CN}(0.6 \mathrm{~mL})$. The mixtures were centrifuged at $1800 \times \mathrm{g}$ for 5 min to remove precipitated material and the supernatants were evaporated by vacuum centrifugation. The residues were reconstituted in $75 \mu \mathrm{L}$ of $0.1 \%$ formic acid in $20 \% \mathrm{CH}_{3} \mathrm{CN}$ for UHPLC-UV-HRMS analysis.

Samples were analyzed on an Orbitrap Elite mass spectrometer in line with a Vanquish UHPLC pump, column oven, and diode array UV/VIS detector (Thermo, Waltham, MA). Samples were injected (10 $\mu \mathrm{L})$ 
onto a Kinetix C18 EC column $(2.3 \times 100$ mm; $2.6 \mu \mathrm{m}$ particle size; Phenomenex, Torrance, CA) equilibrated in a mobile phase comprised of $5 \% \mathrm{CH}_{3} \mathrm{CN}$ in $0.1 \%$ aqueous formic acid at a flow rate of 0.4 $\mathrm{mL} / \mathrm{min}$ and a column oven temperature of $45^{\circ} \mathrm{C}$. This composition was held for $0.5 \mathrm{~min}$ followed by a linear gradient to $65 \% \mathrm{CH}_{3} \mathrm{CN}$ at $4.5 \mathrm{~min}$, a second gradient to $95 \% \mathrm{CH}_{3} \mathrm{CN}$ at $5 \mathrm{~min}$, held at this composition for $2 \mathrm{~min}$ and re-equilibrated at initial conditions for another $2 \mathrm{~min}$. The eluent was directed through the UV detector scanning from 200 to $400 \mathrm{~nm}$ and then into a HESI source on the mass spectrometer. The capillary temperature was $275^{\circ} \mathrm{C}$ and the source temperature was $345^{\circ} \mathrm{C}$. Flows were set at 50,10, and 2 for sheath, sweep, and auxiliary gases, respectively, and the source potential was set to $4 \mathrm{kV}$. The mass spectrometer was set to a resolution of 30000 and scanned from $\mathrm{m} / \mathrm{z} 100$ 500.

Enzyme Kinetics of Linezolid Metabolism. Linezolid (1-400 $\mu \mathrm{M})$ was incubated with human liver microsomes $(2.0 \mathrm{mg} / \mathrm{mL})$, human intestinal microsomes $(2.0 \mathrm{mg} / \mathrm{mL})$ or $\mathrm{P} 450$ enzymes at the following concentrations: CYP1A1 (200 pmol/mL), CYP1B1 (50 pmol/mL), CYP2C8 (200 pmol/mL), CYP2D6 (200 $\mathrm{pmol} / \mathrm{mL})$, CYP2J2 $(25 \mathrm{pmol} / \mathrm{mL})$, CYP3A4 $(200 \mathrm{pmol} / \mathrm{mL})$, CYP3A5 $(200 \mathrm{pmol} / \mathrm{mL})$, and CYP4F2 (100 $\mathrm{pmol} / \mathrm{mL}$ ). The volume of the incubation was $0.05 \mathrm{~mL}$ potassium phosphate buffer $(100 \mathrm{mM}, \mathrm{pH} 7.45)$ containing $\mathrm{MgCl}_{2}(3.3 \mathrm{mM})$ and NADPH (1.3 mM). Incubations were carried out for 40 min (previously established to provide a linear increase in metabolites vs time) and terminated with the addition of 0.05 $\mathrm{mL}$ of $\mathrm{CH}_{3} \mathrm{CN} / \mathrm{HCOOH} / \mathrm{H}_{2} \mathrm{O}$ (40:5:55) The mixtures were centrifuged at $1800 \times \mathrm{g}$ for $5 \mathrm{~min}$ to remove precipitated material and the supernatants were analyzed for 2-hydroxylinezolid and desethylenelinezolid by UHPLC-HRMS. 
Inhibition of Linezolid Metabolism by LKY-047, Sesamin, and 1-(3-Chlorophenyl)-3-phenylurea. Inhibition of linezolid metabolism by recombinant CYP2J2, CYP4F2, and CYP1B1 was evaluated for LKY047, sesamin, and 1-(3-chlorophenyl)-3-phenylurea, respectively. Concentrations of the enzymes were 25,100 , and $100 \mathrm{pmol} / \mathrm{mL}$ respectively. Concentration ranges tested for the inhibitors, at 11 concentrations, were $0.02-200 \mu \mathrm{M}$ for LKY-047, 0.004-40 $\mu \mathrm{M}$ for sesamin, and 0.01-100 $\mu \mathrm{M}$ for 1-(3chlorophenyl)-3-phenylurea. Incubations were conducted, processed, and analyzed as described above. The concentration of linezolid used was $40 \mu \mathrm{M}$, and this approximates the unbound mean steady-state $\mathrm{C}_{\max }$ following administration of $625 \mathrm{mg}$ BID (Stalker and Jungbluth, 2003). These three inhibitors were also tested using human liver microsomes $(2.0 \mathrm{mg} / \mathrm{mL})$ at 22 concentrations ranging from $0.02-200 \mu \mathrm{M}$ for LKY-047, $0.008-80 \mu \mathrm{M}$ for sesamin, and 0.01-100 $\mu \mathrm{M}$ for 1-(3-chlorophenyl)-3-phenylurea. To test for selectivity, these three inhibitors were also tested at a single concentration each (60 $\mu \mathrm{M} \mathrm{LKY-047,30}$ $\mu \mathrm{M}$ sesamin or $10 \mu \mathrm{M}$ 1-(3-chlorophenyl)-3-phenylurea) for their effect on recombinant enzymes shown to metabolize linezolid: CYP1A1 (200 pmol/mL), CYP1B1 (50 pmol/mL), CYP2C8 (200 pmol/mL), CYP2D6 (200 pmol/mL), CYP2J2 (25 pmol/mL), CYP3A4 (200 pmol/mL), CYP3A5 (200 pmol/mL), and CYP4F2 (100 $\mathrm{pmol} / \mathrm{mL})$.

UHPLC-MS Assay for 2-Hydroxylinezolid and Desethylenelinezolid. 2-Hydroxylinezolid and desethylenelinezolid were quantitated from an 11-point standard curve ranging from 4.0 to $8000 \mathrm{nM}$. Standards $(0.05 \mathrm{~mL})$ were treated with $0.05 \mathrm{~mL}$ of $\mathrm{CH}_{3} \mathrm{CN} / \mathrm{HCOOH} / \mathrm{H}_{2} \mathrm{O}(40: 5: 55)$, the mixtures were centrifuged at $1800 \times \mathrm{g}$ for $5 \mathrm{~min}$ to remove precipitated material, and the supernatants were analyzed on an Orbitrap Elite mass spectrometer in line with a Vanquish UHPLC, column oven, and diode array UV/VIS detector (Thermo, Waltham, MA). Samples were injected (10 $\mu \mathrm{L})$ onto a Kinetix C18 EC column (2.3 x $100 \mathrm{~mm} ; 2.6 \mu \mathrm{m}$ particle size; Phenomenex, Torrance, CA) equilibrated in a mobile phase 
comprised of $10 \% \mathrm{CH}_{3} \mathrm{CN}$ in $0.1 \%$ aqueous formic acid at a flow rate of $0.4 \mathrm{~mL} / \mathrm{min}$ and a column temperature of $45^{\circ} \mathrm{C}$. This composition was held for $0.5 \mathrm{~min}$ followed by a linear gradient to $65 \% \mathrm{CH}_{3} \mathrm{CN}$ at $1.5 \mathrm{~min}$, a $1 \mathrm{~min}$ wash at $95 \% \mathrm{CH}_{3} \mathrm{CN}$ and re-equilibrated at initial conditions for another $2 \mathrm{~min}$. The eluent was directed into a HESI source on the mass spectrometer. The capillary temperature was $275^{\circ} \mathrm{C}$ and the source temperature was $345^{\circ} \mathrm{C}$. Flows were set at 50,10 , and 2 for sheath, sweep, and auxiliary gases, respectively, and the source potential was set to $4 \mathrm{kV}$. The mass spectrometer was set to a resolution of 30000 and scanned from $\mathrm{m} / \mathrm{z}$ 300-400. Peak areas were measured from extracted ion chromatograms of $\mathrm{m} / \mathrm{z} 354.1457$ (2-hydroxylinezolid) and $\mathrm{m} / \mathrm{z} 312.1355$ (desethylenelinezolid) at a tolerance of 5 ppm using QuanBrowser in Xcalabur (Version 4.2.28.14; Thermo, Waltham, MA). Retention times were 2.7 and 1.9 min for 2-hydroxylinezolid and desethylenelinezolid, respectively. The calibration curves were generated from peak areas using the interpolation function in GraphPad Prism (v9; Graph Pad, San Diego, CA) using hyperbolic fitting.

Data Analysis. Enzyme kinetic and inhibition parameters were evaluated using GraphPad Prism (v9; Graph Pad, San Diego, CA). Intrinsic clearance values were calculated as the ratio of $V_{\max } / K_{M}$. When $K_{M}$ values were estimated to be greater than the highest substrate concentration evaluated, individual values for $K_{M}$ and $V_{\max }$ were not reported but instead reported as the composite ratio $\left(V_{\max } / K_{M}\right)$ representing an approximation of intrinsic clearance. Inhibition curves were fitted to four or six parameter binding curves in order to delineate complex relationships of $\%$ of control activity vs inhibitor concentration. All enzyme kinetic and inhibition determinations were made from single experiments run in triplicate. 
DMD Fast Forward. Published on January 18, 2022 as DOI: 10.1124/dmd.121.000776

This article has not been copyedited and formatted. The final version may differ from this version. 


\section{RESULTS}

Metabolite Profiles of Linezolid. Seventeen individual P450 enzymes were evaluated for their ability to generate metabolites of linezolid. Of these seventeen, CYP2J2, CYP4F2, and CYP1B1 yielded the largest metabolite peaks, with CYP2J2 being the enzyme that metabolized linezolid the most (Figure 2). Other P450 enzymes that were able to generate metabolites of linezolid included CYP1A1, CYP2C8, CYP2D6, CYP3A4, and CYP3A5, but to a far lesser amount. CYP1A2, CYP2A6, CYP2B6, CYP2C9, CYP2C18, CYP2C19, CYP2E1, CYP3A7, and CYP4A11 did not generate metabolites of linezolid. Among the eight that did generate metabolites of linezolid, there were two metabolites common to all that were identified as 2hydroxylinezolid and desethylenelinezolid, both arising from metabolism of the morpholine ring. 2Hydroxylinezolid was the major initial metabolite previously identified (and referred to as M1 by Wynalda, et al., 2000), while the deethyleneated product arises through a series of oxidation reactions that could come from 2-hydroxylinezolid and/or a hypothetical intermediate metabolite arising from oxidation on the morpholine carbon(s) alpha to the nitrogen. The latter intermediate metabolite was not observed. While both metabolites were dominant in the profile generated from CYP2J2, CYP4F2 favored the 2-hydroxylation product while CYP1B1 favored the desethylene product. Additionally, CYP1B1 was also shown to generate other minor metabolites with protonated molecular ions consistent

with the addition of oxygen. These coeluted with compounds wherein the hydroxylation was on the fluorophenyl ring at positions meta- and para- to the fluorine atom. These were not pursued further. In comparison, human liver microsomes also generated 2-hydroxylinezolid and desethylenelinezolid as the major metabolites.

Enzyme Kinetics of Linezolid Metabolism. Since eight enzymes were shown to have the capability to generate metabolites of linezolid, these were evaluated for enzyme kinetics of 2-hydroxylation and 
deethyleneation reactions. Plots are shown in Figure 3 and the parameters are listed in Table 1. For several of the enzymes, $\mathrm{K}_{M}$ values were greater than the highest substrate concentration evaluated precluding reporting the individual $\mathrm{K}_{\mathrm{M}}$ and $\mathrm{V}_{\max }$ values, so these were reported as composite $\mathrm{CL}_{\text {int }}$ values. Consistent with the metabolite profiles (Figure 2), CYP2J2 yielded the highest values for intrinsic clearance. For desethylenation, the $\mathrm{CL}_{\text {int }}$ value for CYP2J2 was 20 -fold higher than the next enzymes (CYP1B1 and CYP3A4) and for 2-hydroxylation the $\mathrm{CL}_{\text {int }}$ value was 6-fold greater than the next most active enzyme, CYP4F2. CYP2J2 was the only enzyme for which a $K_{M}$ value was reportable for 2hydroxylation. The rank order of quantitative importance for 2-hydroxylation was $2 \mathrm{~J} 2>>4 \mathrm{~F} 2>2 \mathrm{C} 8>\mid \mathrm{B} 1 \approx 2 \mathrm{D} 6 \approx 3 \mathrm{~A} 4>1 \mathrm{~A} 1>3 \mathrm{~A} 5 . \quad$ For deethyleneation, the order was $2 \mathrm{~J} 2>1 \mathrm{~B} 1 \approx 3 \mathrm{~A} 4>2 \mathrm{D} 6 \approx 1 \mathrm{~A} 1>3 \mathrm{~A} 5>2 \mathrm{C} 8>4 \mathrm{~F} 2$.

Enzyme kinetics for these two reactions were also evaluated in human liver and intestinal microsomes (Figure 4; Table 1). In liver microsomes, the $\mathrm{CL}_{\text {int }}$ values were almost the same for the two products. However for intestine microsomes, the deethyleneation was nearly ten-fold greater than the 2hydroxylation.

Inhibition of Linezolid Metabolism by Selective Inhibitors of CYP2J2, CYP4F2, and CYP1B1. LKY-047, sesamin, and 1-(3-chlorophenyl)-3-phenylurea were evaluated as inhibitors of linezolid metabolism catalyzed by CYP2J2, CYP4F2, and CYP1B1, respectively, and IC 50 curves are in Figure 5. In CYP2J2, LKY047 caused complete inhibition of both 2 -hydroxylation and deethyleneation with mean $(95 \% \mathrm{Cl}) \mathrm{IC}_{50}$ values of $3.21 \mu \mathrm{M}(2.68-3.84)$ and $2.04 \mu \mathrm{M}$ (1.56-2.87), respectively. For sesamin, a time-dependent inhibitor of CYP4F2, complete inhibition of CYP4F2 catalyzed linezolid 2-hydroxylase activity was observed with an $\mathrm{IC}_{50}$ value of $0.92 \mu \mathrm{M}(0.76-1.1)$ however the desethylenation reaction was only 
inhibited maximally by about 50\%. For 1-(3-chlorophenyl)-3-phenylurea, complete inhibition of both linezolid metabolic reactions by CYP1B1 was observed with $\mathrm{IC}_{50}$ values of $0.81 \mu \mathrm{M}(0.73-0.91)$ and 0.58 $\mu \mathrm{M}(0.46-0.72)$ for 2-hydroxylation and deethylenation, respectively.

This initial exploration of the inhibitory potencies of these three compounds for their respective target P450 enzymes led to their use to evaluate inhibition in liver microsomes (Figure 5). For LKY-047, linezolid 2-hydroxylation was maximally inhibited by $57 \%$ with an $\mathrm{IC}_{50}$ value of $14 \mu \mathrm{M}$ which suggests inhibition of CYP2J2. However, desethylenation was inhibited only at high inhibitor concentrations. For sesamin, complete inhibition was observed in human liver microsomes for 2-hydroxylation, with an $\mathrm{IC}_{50}$ of $5.1 \mu \mathrm{M}$. Inhibition of desethyleneation was weaker. For 1-(3-chlorophenyl)-3-phenylurea, inhibition of linezolid metabolism in liver microsomes was only observed at inhibitor concentrations much greater than those that demonstrated effects in recombinant CYP1B1. Overall, these data suggest that in human liver microsomes CYP2J2 and CYP4F2 contribute to the metabolism of linezolid but that CYP1B1 does not.

Test of Selectivity of CYP2J2, CYP4F2, and CYP1B1 Inhibitors. The three inhibitors LKY-047, sesamin, and 1-(3-chlorophenyl)-3-phenylurea were tested as inhibitors of linezolid metabolism catalyzed by the other P450 enzymes demonstrated to metabolize linezolid (i.e. CYP1A1, CYP2C8, CYP2D6, CYP3A4, and CYP3A5), to verify or refute that these inhibitors are selective for their intended enzymes (Figure 6). The concentrations of the inhibitors evaluated were those that provided at least $90 \%$ inhibition of the targeted enzyme: $60 \mu \mathrm{M}$ for LKY-047, $30 \mu \mathrm{M}$ for sesamin, and $10 \mu \mathrm{M}$ for 1-(3-chlorophenyl)-3phenylurea. LKY-047 most potently inhibited CYP2J2, however there was considerable inhibition of CYP4F2 and 1B1. Interestingly, LKY-047 appeared to stimulate CYP3A activity. Sesamin robustly 
inhibited not only CYP4F2 but also CYP2J2, and weakly inhibited several of the other P450s. 1-(3Chlorophenyl)-3-phenylurea mostly inhibited only CYP1B1.

Effect of a Panel of Cytochrome P450 Inhibitors on Human Liver Microsomal Metabolism of Linezolid. In recombinant cytochrome P450s, five enzymes demonstrated a capability to metabolize linezolid in addition to CYP2J2, CYP4F2, and CYP1B1 (see above). To determine whether these other enzymes are involved in linezolid metabolism in liver microsomes, P450 selective inhibitors for these other five enzymes were tested (Figure 7). $\alpha$-Naphthoflavone (CYP1A1), gemfibrozil glucuronide (CYP2C8), quinidine (CYP2D6), ketoconazole (CYP3A), troleandomycin (CYP3A), and cyp3cide (CYP3A4) were evaluated at concentrations known to inhibit these enzymes, and compared to LKY-047, sesamin, and 1(3-chlorophenyl)-3-phenylurea. These other inhibitors had little to no effect on linezolid 2-hydroxylation and some effects on deethyleneation. 


\section{DISCUSSION}

Previous in vitro experimentation could not readily identify specific P450 enzymes responsible for metabolism of linezolid and it was hypothesized that morpholine oxidation could occur via the action of reactive oxygen species that can be generated as side products during in vitro incubations (Wynalda, et al., 2000). An attempt was made to probe this possibility in a clinical pharmacokinetic study wherein linezolid was coadministered with high doses of the antioxidant vitamins $C$ and $E$, however no impact was observed (Gordi, et al., 2003). Other drug interaction studies (Bolhuis, et al., 2013; Gandelman, et al., 2011) suggested a minor role for CYP3A. During a reevaluation of reaction phenotyping methods employed in our laboratories, it was uncovered that CYP2J2, CYP4F2, and CYP1B1 could readily metabolize linezolid, especially CYP2J2. Ironically, these three enzymes were not among the comprehensive list of P450 enzymes investigated by Wynalda, et al., (2000). This observation spurred the present investigation in an attempt to finally identify the enzymes important in linezolid metabolism.

CYP2J2 metabolized linezolid to the 2-hydroxy and desethylene metabolites faster than any other P450 enzyme. Compared to the main drug-metabolizing P450 enzymes, less is known about CYP2J2. It is expressed in the liver (Yamazaki, et al., 2006), intestine (Paine, et al., 2006), and heart (Delozier, et al., 2007) and in the latter case may be involved in the regulation of bioactive epoxyeicosatrienoic acids (Murray, 2016). It has been shown to metabolize drugs such as terfenadine, astemazole, and ebsastine (Lee, et al., 2010; Matsumato, et al, 2002). The inhibitor LKY-047 (Phuc, et al., 2017) was employed to delineate the role of CYP2J2 in linezolid metabolism in liver microsomes. LKY-047 was confirmed as an inhibitor of recombinant CYP2J2 with a potency similar to that previously reported (Figure 5). The fit of the inhibition curve in human liver microsomes (Figure 5) supports that CYP2J2 has about a 50-60\% 
contribution to linezolid 2-hydroxylation, the initial step in linezolid metabolism. Its quantitative role in the secondary metabolism to desethylenelinezolid is not as clear, even though this reaction occurred in incubations containing recombinant CYP2J2. An important role for CYP2J2 in linezolid clearance does not contradict the previously reported clinical observations (Bolhuis, et al., 2013; Gandelman, et al., 2011) and in vitro study (Wynalda, et al., 2000). The current data support an important role for this enzyme in linezolid metabolic clearance.

CYP4F2 was also shown to be able to metabolize linezolid to the 2-hydroxy metabolite, with a lower conversion to the desethylene metabolite. CYP4F enzymes are more associated with the metabolism of fatty acids than drugs, although they have been shown to metabolize some drugs, like parfuramidine and fingolimod (Kalsotra and Strobel, 2006; Wang, et al., 2007; Jin, et al, 2011). CYP4F2 is expressed in liver and kidney of humans. While the specific activity of CYP4F2 for linezolid 2-hydroxylation was 6-fold lower than CYP2J2, the expression level in liver for CYP4F2 is greater, ranging up to $30 \mathrm{pmol} / \mathrm{mg}$ protein (Michaels and Wang, 2014). Sesamin, a known inhibitor of CYP4F2 (Watanabe, et al., 2020) was shown to cause nearly complete inhibition of linezolid 2-hydroxylation in both recombinant CYP4F2 and human liver microsomes (Figure 5). At first glance, this could be viewed as contrasting the result obtained for LKY-047 in liver microsomes showing the aforementioned 50-60\% contribution by CYP2J2. However, sesamin was subsequently tested as an inhibitor for CYP2J2 plus the other enzymes shown to catalyze any level of linezolid metabolism, and it was shown to be a robust inhibitor of CYP2J2 (Figure 6). Thus, the full inhibition observed in liver microsomes for sesamin is likely due to simultaneous inhibition of both CYP4F2 and CYP2J2. Furthermore, the small effect of ketoconazole on linezolid metabolism in human liver microsomes could be due to inhibition of CYP4F2 and not CYP3A4, since ketoconazole was 
shown to impact the pharmacokinetics of the CYP4F2 metabolized drug fingolimod (Kovarik, et al., 2009).

CYP1B1 was a third P450 enzyme shown to metabolize linezolid that had not been previously evaluated by Wynalda, et al (2000). It actually generated not only the 2-hydroxy and desethylene metabolites, but two other previously undescribed hydroxy metabolites as well. However, CYP1B1 is not highly expressed in liver and the lack of an effect of the CYP1B1 inhibitor 1-(3-chlorophenyl)-3-phenylurea in liver microsomes is consistent with this enzyme not having a substantial role in linezolid clearance, at least not hepatic clearance. Five other P450 enzymes demonstrated a capability to metabolize linezolid: CYP1A1, CYP2C8, CYP2D6, CYP3A4, and CYP3A5, however the inhibition data using selective inhibitors for these enzymes ( $\alpha$-naphthoflavone for CYP1A1; gemfibrozil glucuronide for CYP2C8; quinidine for CYP2D6; and three inhibitors for CYP3A; Figure 7) support that none of these enzymes plays a large role in linezolid clearance via the 2-hydroxylation pathway. There could be some role for these in subsequent reactions that lead to desethylene linezolid. Also, CYP1A1 is expressed in extrahepatic tissues and not liver and thus could have still some contribution to linezolid metabolism in vivo.

It is challenging to generate reliable quantitative $f_{m}$ estimates for enzymes not commonly encountered in drug metabolism, like CYP2J2, CYP4F2, and CYP1B1. Experience with the inhibitor tools for these enzymes is not as great as it is for inhibitors for the more commonly encountered drug metabolizing P450 enzymes (e.g. quinidine for CYP2D6 or ketoconazole for CYP3A, etc). The findings in this study support that the initial pathway of linezolid metabolism, 2-hydroxylation, has large contributions from CYP2J2 and CYP4F2 in liver. Subsequent metabolism to the desethylene metabolite may be catalyzed by several P450 enzymes. Further investigation should address the potential contributions of extrahepatic 
tissues to linezolid metabolism since some of these enzymes (CYP1A1, CYP1B1, and CYP2J2) are expressed in tissues other than liver. The findings of potentially meaningful contributions of CYP2J2 and CYP4F2 to linezolid metabolic clearance should not result in any changes in prescribing practice for this drug, since there are not any known major drug-drug interactions or pharmacogenetic impacts on these enzymes.

ACKNOWLEDGMENTS: The author wishes to thank Matt Cerny for preparing and sharing LKY-047, Greg Walker for quantitative NMR analysis of the biosynthesized linezolid metabolites, and Sharon Ripp for reviewing the draft manuscript.

AUTHORSHIP CONTRIBUTIONS: The sole author of this paper participated in research design, conducted experiments, performed data analysis, and wrote the manuscript.

FINANCIAL STATEMENT: The authors is an employee of and shareholder in Pfizer Inc.

FUNDING: This work received no external funding. 


\section{REFERENCES}

Bolhuis MS, van Altena R, van Soolingen D, de Lange WC, Uges DR, van der Werf TS, Kosterink JG, Alffenaar JW. (2013) Clarithromycin increases linezolid exposure in multidrug-resistant tuberculosis patients. Eur Respir J. 42:1614-21.

Delozier TC, Kissling GE, Coulter SJ, Dai D, Foley JF, Bradbury JA, Murphy E, Steenbergen C, Zeldin DC, Goldstein JA. (2007) Detection of human CYP2C8, CYP2C9, and CYP2J2 in cardiovascular tissues. Drug Metab Dispos 35:682-8.

Egle H, Trittler R, Kümmerer K, Lemmen SW. (2005) Linezolid and rifampin: Drug interaction contrary to expectations? Clin Pharmacol Ther 77:451-3.

Gandelman K, Zhu T, Fahmi OA, Glue P, Lian K, Obach RS, Damle B. (2011) Unexpected effect of rifampin on the pharmacokinetics of linezolid: in silico and in vitro approaches to explain its mechanism. $J$ Clin Pharmacol. 51:229-36.

Gordi T, Tan LH, Hong C, Hopkins NJ, Francom SF, Slatter JG, Antal EJ. (2003) The pharmacokinetics of linezolid are not affected by concomitant intake of the antioxidant vitamins $\mathrm{C}$ and E. J Clin Pharmacol. 43:1161-7.

Hashemian SMR, Farhadi T, Ganjparvar M. (2018) Linezolid: a review of its properties, function, and use in critical care. Drug Des Devel Ther. 18:1759-1767.

Jin Y, Zollinger M, Borell H, Zimmerlin A, Patten CJ. (2011) CYP4F enzymes are responsible for the elimination of fingolimod (FTY720), a novel treatment of relapsing multiple sclerosis. Drug Metab Dispos. 39:191-8.

Kalsotra A, and Strobel HW. (2006) Cytochrome P450 4F subfamily: at the crossroads of eicosanoid and drug metabolism. Pharmacol Ther. 112:589-611.

Kovarik JM, Dole K, Riviere GJ, Pommier F, Maton S, Jin Y, Lasseter KC, Schmouder RL. (2009) Ketoconazole increases fingolimod blood levels in a drug interaction via CYP4F2 inhibition. J Clin Pharmacol. 49:212-8 
Lee CA, Neul D, Clouser-Roche A, Dalvie D, Wester MR, Jiang Y, Jones JP 3rd, Freiwald S, Zientek M, Totah RA. (2010) Identification of novel substrates for human cytochrome P450 2J2. Drug Metab Dispos. 38:347-56.

Matsumoto S, Hirama T, Matsubara T, Nagata K, Yamazoe Y. (2002) Involvement of CYP2J2 on the intestinal first-pass metabolism of antihistamine drug, astemizole. Drug Metab Dispos. 30:1240-5.

Michaels S and Wang MZ. (2014) The revised human liver cytochrome P450 "Pie": absolute protein quantification of CYP4F and CYP3A enzymes using targeted quantitative proteomics. Drug Metab Dispos. 42:1241-51.

Mohd Siddique MU, McCann GJ, Sonawane V, Horley N, Williams IS, Joshi P, Bharate SB, Jayaprakash V, Sinha BN, Chaudhuri B. Biphenyl urea derivatives as selective CYP1B1 inhibitors. Org Biomol Chem. 2016 Sep 26;14(38):8931-8936.

Paine MF, Hart HL, Ludington SS, Haining RL, Rettie AE, Zeldin DC. (2006) The human intestinal cytochrome P450 "pie". Drug Metab Dispos. 34:880-6.

Phuc NM, Wu Z, O Y, Lee JH, Oh S, Song GY, Liu KH. (2017) LKY-047: First Selective Inhibitor of Cytochrome P450 2J2. Drug Metab Dispos. 45:765-769.

Slatter JG, Stalker DJ, Feenstra KL, Welshman IR, Bruss JB, Sams JP, Johnson MG, Sanders PE, Hauer MJ, Fagerness PE, Stryd RP, Peng GW, Shobe EM. (2001) Pharmacokinetics, metabolism, and excretion of linezolid following an oral dose of $[(14) \mathrm{C}]$ linezolid to healthy human subjects. Drug Metab Dispos. 29:1136-45.

Stalker DJ and Jungbluth GL. (2003) Clinical pharmacokinetics of linezolid, a novel oxazolidinone antibacterial. Clin Pharmacokinet. 42:1129-40.

Walker GS, Bauman JN, Ryder TF, Smith EB, Spracklin DK, Obach RS. (2014) Biosynthesis of drug metabolites and quantitation using NMR spectroscopy for use in pharmacologic and drug metabolism studies. Drug Metab Dispos. 42:1627-39. 
Wang MZ, Wu JQ, Bridges AS, Zeldin DC, Kornbluth S, Tidwell RR, Hall JE, Paine MF. (2007) Human enteric microsomal CYP4F enzymes O-demethylate the antiparasitic prodrug pafuramidine. Drug Metab Dispos. 35:2067-75.

Watanabe H, Yamaori S, Kamijo S, Aikawa K, Ohmori S. (2020) In Vitro Inhibitory Effects of Sesamin on CYP4F2 Activity. Biol Pharm Bull. 43:688-692.

Wynalda MA, Hauer MJ, Wienkers LC. (2000) Oxidation of the novel oxazolidinone antibiotic linezolid in human liver microsomes. Drug Metab Dispos. 28:1014-7.

Yamazaki H, Okayama A, Imai N, Guengerich FP, Shimizu M. (2006) Inter-individual variation of cytochrome P4502J2 expression and catalytic activities in liver microsomes from Japanese and Caucasian populations. Xenobiotica. 36:1201-9. 


\section{FIGURE LEGENDS}

Figure 1. Metabolism of linezolid to 2-hydroxylinezolid and desethylenlinezolid, and structures of CYP2J2, CYP4F2, and CYP1B1 inhibitors.

Figure 2. HPLC-UV profiles of linezolid metabolism. Peaks for linezolid and its metabolites are denoted; other peaks visible in these traces were not drug-related.

Figure 3. Substrate saturation plots for linezolid metabolism by eight cytochrome P450 enzymes. 2Hydroxylinezolid is in red and desethylenelinezolid is in blue.

Figure 4. Substrate saturation plots for linezolid metabolism by human liver and intestinal microsomes. 2-Hydroxylinezolid is in red and desethylenelinezolid is in blue.

Figure 5. IC 50 curves for LKY-047, sesamin, and 1-(3-chlorophenyl)-3-phenylurea on linezolid metabolism catalyzed by CYP2J2, CYP4F2, CYP1B1, and human liver microsomes. 2-Hydroxylinezolid is in red and desethylenelinezolid is in blue.

Figure 6. Inhibition of linezolid metabolism catalyzed by eight cytochrome P450 enzymes. Concentrations of inhibitors used were 60, 30, and $10 \mu \mathrm{M}$ for LKY-047, sesamin, and 1-(3-chlorophenyl)3-phenylurea, respectively. Asterisks indicate data with $p \leq 0.01$ vs control.

Figure 7. Inhibition of linezolid metabolism catalyzed by human liver microsomes by several cytochrome P450 inhibitors. Asterisks indicate data with $p \leq 0.01$ vs control. 
TABLE 1. Summary of Enzyme Kinetic Parameters for Linezolid Metabolism ${ }^{d}$

\begin{tabular}{|c|c|c|c|c|c|c|}
\hline \multirow[b]{2}{*}{ Enzyme } & \multicolumn{3}{|c|}{ 2-Hydroxylinezolid } & \multicolumn{3}{|c|}{ Desethyenelinezolid } \\
\hline & $\mathrm{K}_{\mathrm{M}}^{\mathrm{b}}$ & $\mathrm{V}_{\max }^{\mathrm{c}}$ & $\mathrm{CL}_{\text {int }}^{\mathrm{c}}$ & $\mathrm{K}_{\mathrm{M}}^{\mathrm{b}}$ & $\mathrm{V}_{\max }{ }^{\mathrm{c}}$ & $\mathrm{CL}_{\text {int }}^{\mathrm{c}}$ \\
\hline CYP1A1 & $N D^{a}$ & ND & 0.120 & $233(154-370)$ & 0.550 迎.449-0.710) & 2.36 \\
\hline CYP1B1 & ND & ND & 0.383 & $196(159-243)$ & 0.868 (\$p.786-0.969) & 4.43 \\
\hline CYP2D6 & ND & ND & 0.391 & ND & 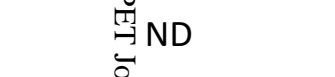 & 2.91 \\
\hline CYP2J2 & $124(109-141)$ & $2.66(2.52-2.80)$ & 21.4 & $23.7(20.1-27.8)$ & 2.28 灵2.19-2.39) & 96.2 \\
\hline CYP3A4 & ND & ND & 0.294 & $258(211-320)$ & 1.12 १1.01-1.26) & 4.34 \\
\hline CYP3A5 & ND & ND & 0.0485 & ND & 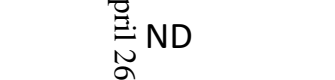 & 1.32 \\
\hline Human Intestine Microsomes & ND & ND & 0.0071 & ND & ND & 0.0757 \\
\hline
\end{tabular}

\footnotetext{
${ }^{\mathrm{a}} \mathrm{ND}$; individual enzyme kinetic parameters were not able to be determined since estimated $\mathrm{K}_{\mathrm{M}}$ was greater than the highest substrate concentration evaluated.

${ }^{b}$ All $K_{M}$ units are $\mu \mathrm{M}$.

${ }^{c}$ For recombinant $\mathrm{P} 450$ data $\mathrm{V}_{\max }$ units are $\mathrm{pmol} / \mathrm{min} / \mathrm{pmol} \mathrm{P} 450$ and $\mathrm{CL}_{\text {int }}$ units are $\mu \mathrm{L} / \mathrm{min} / \mathrm{nmol} \mathrm{P} 450$. For microsomal data, $\mathrm{V}_{\max }$ units are $\mathrm{pmol} / \mathrm{min} / \mathrm{mg}$ protein and $\mathrm{CL}_{\text {int }}$ units are $\mu \mathrm{L} / \mathrm{min} / \mathrm{mg}$ protein.

${ }^{d}$ Values in parentheses are the $95 \%$ confidence intervals. All data were rounded to three significant digits.
} 


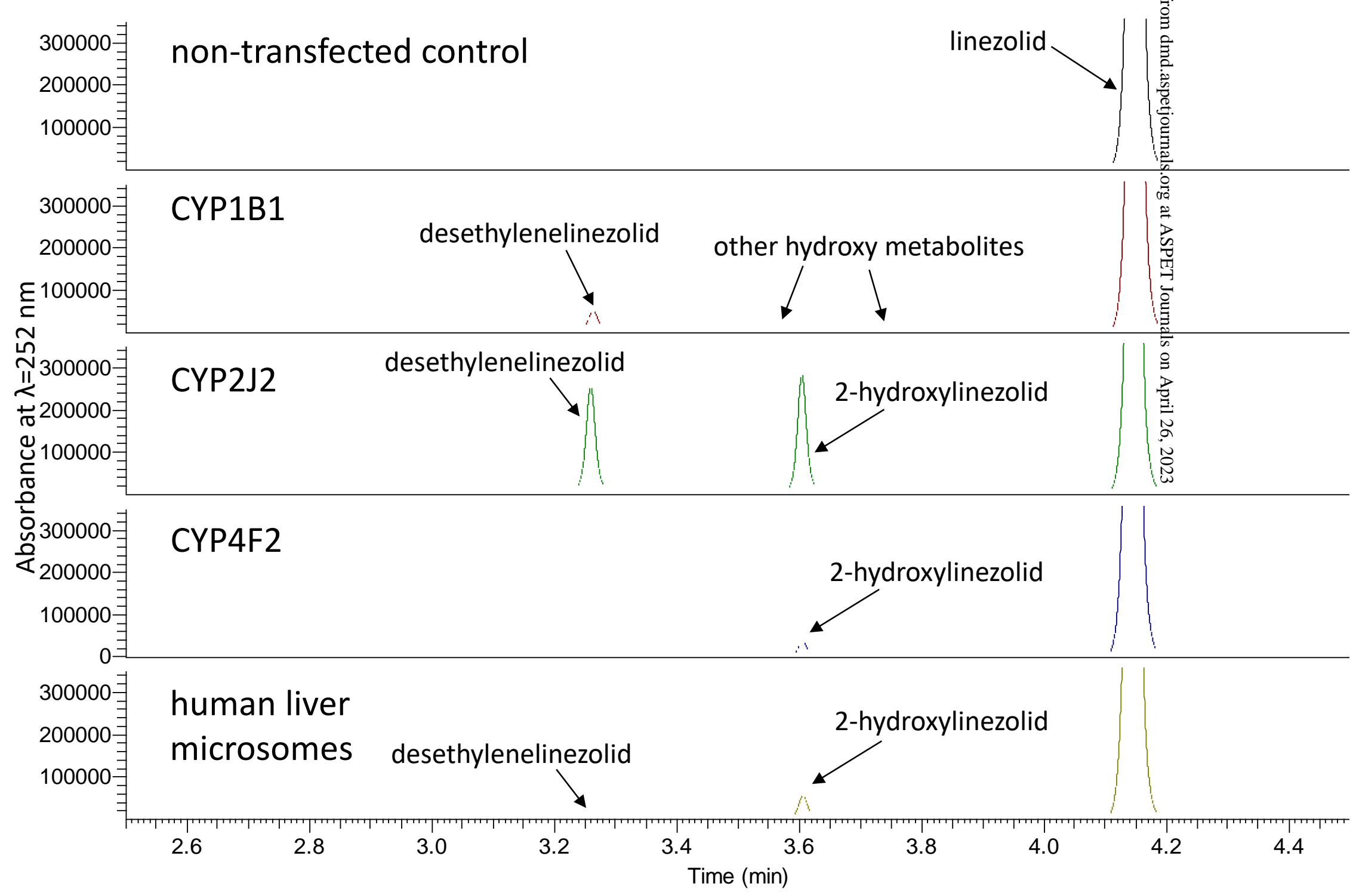

\section{Figure 2}




\section{CYP1A1}

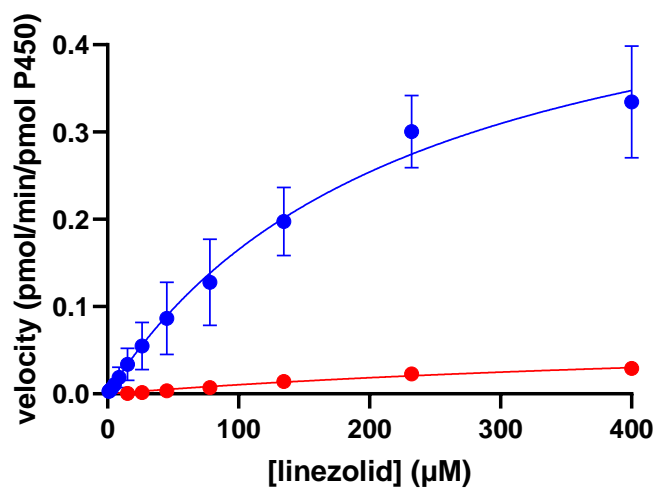

CYP2C8

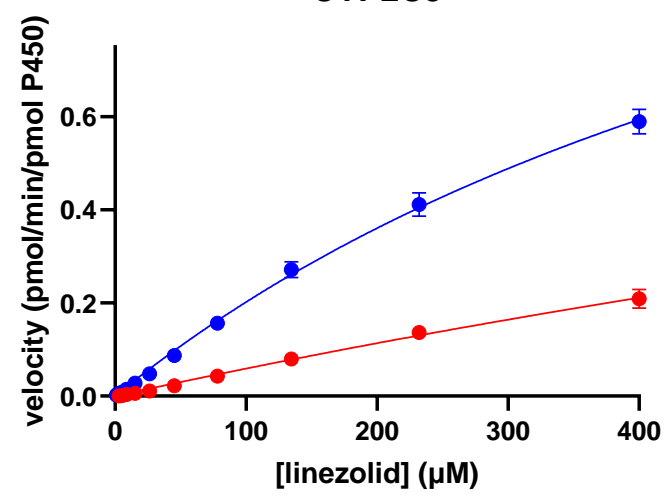

CYP2J2

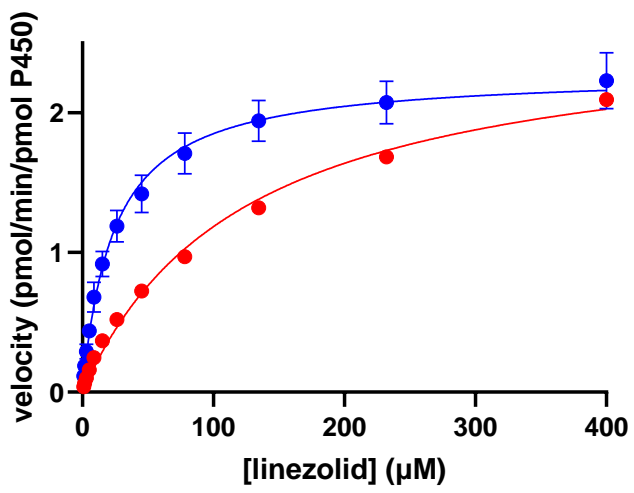

CYP3A5

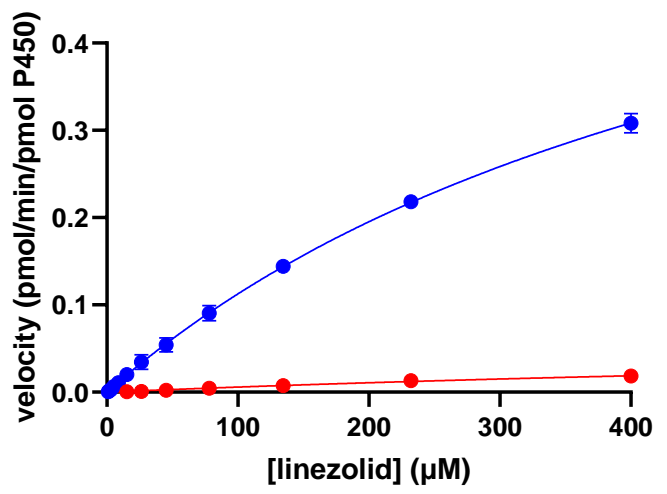

CYP1B1

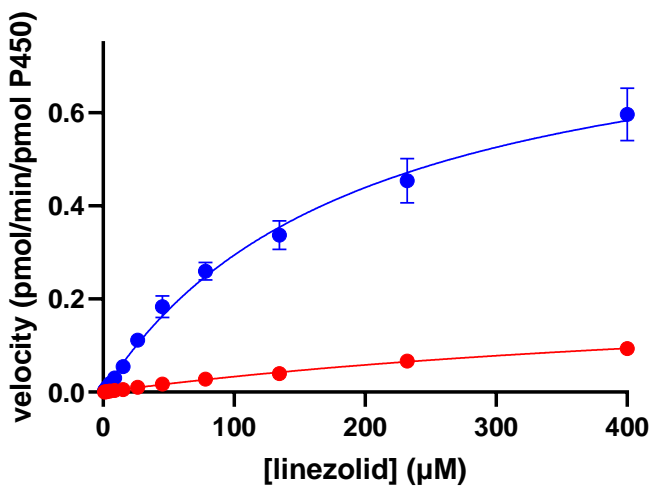

CYP2D6

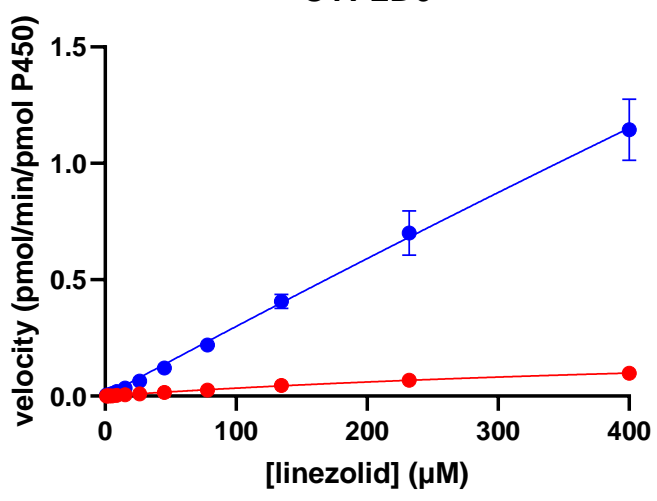

CYP3A4

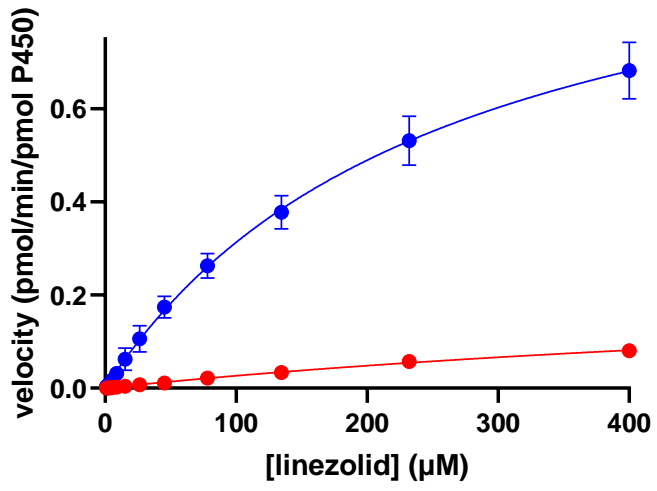

CYP4F2

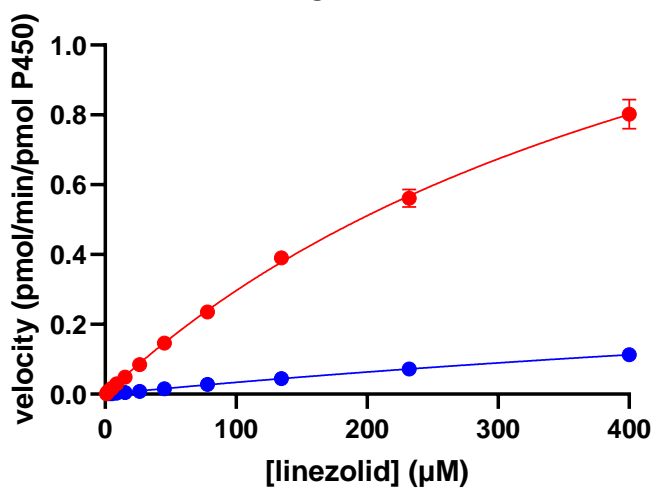



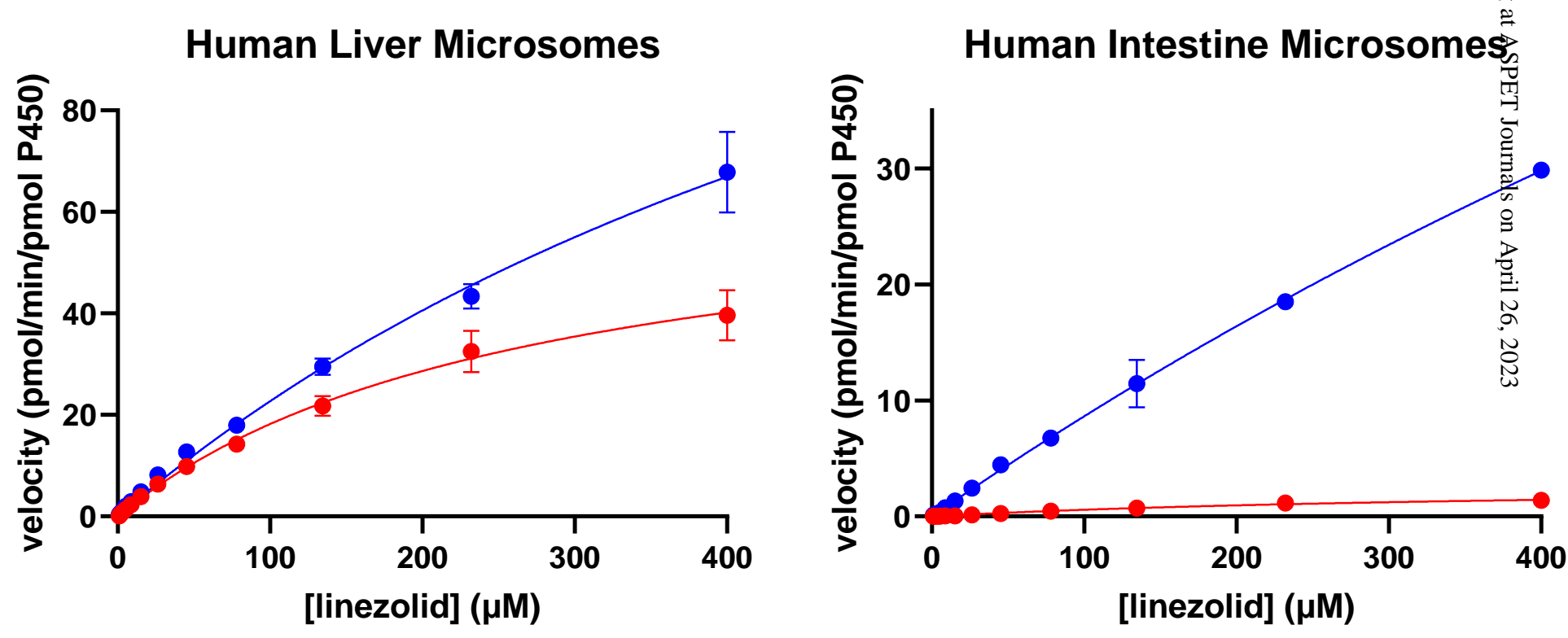

Figure 4 

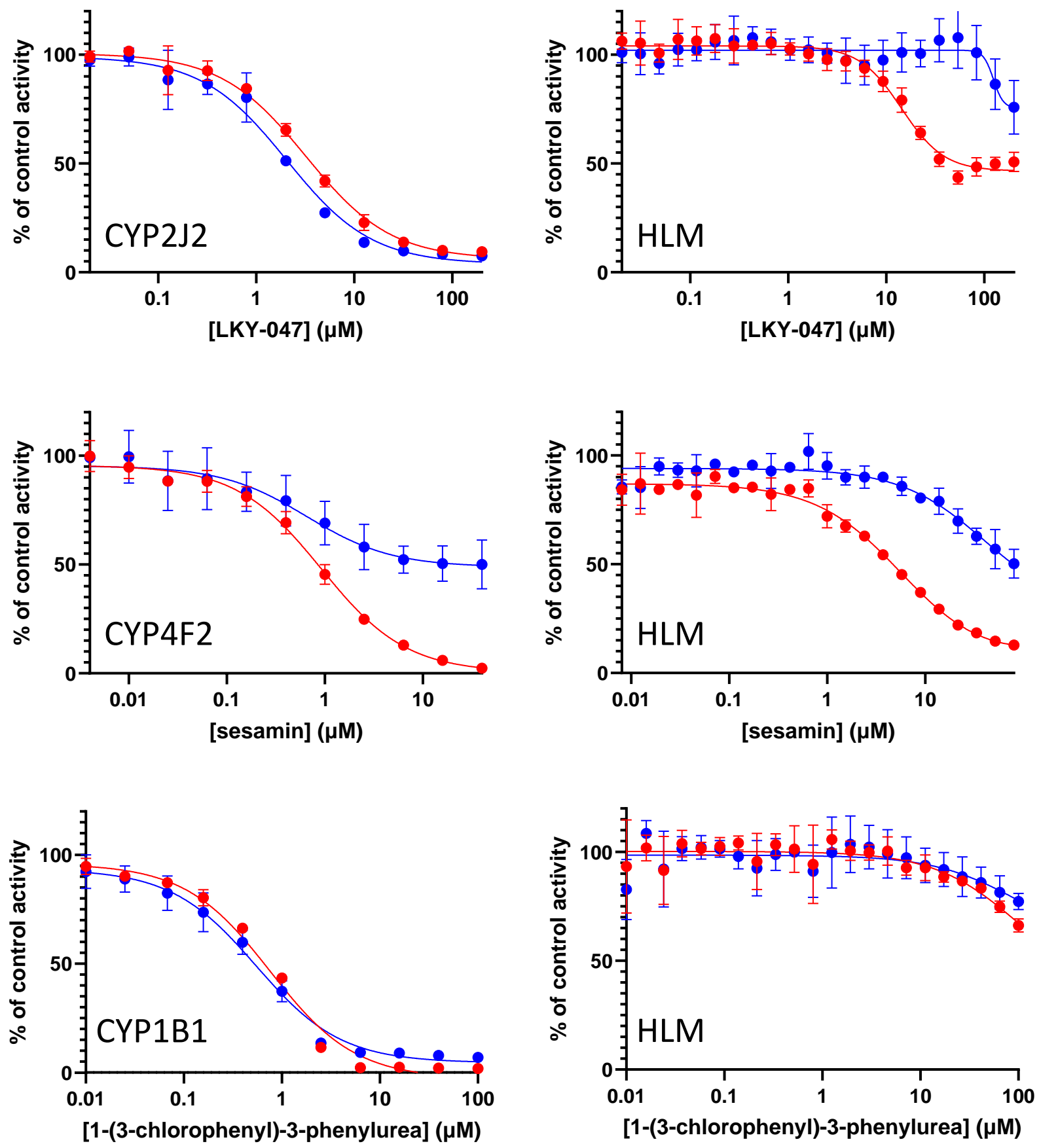

Figure 5 


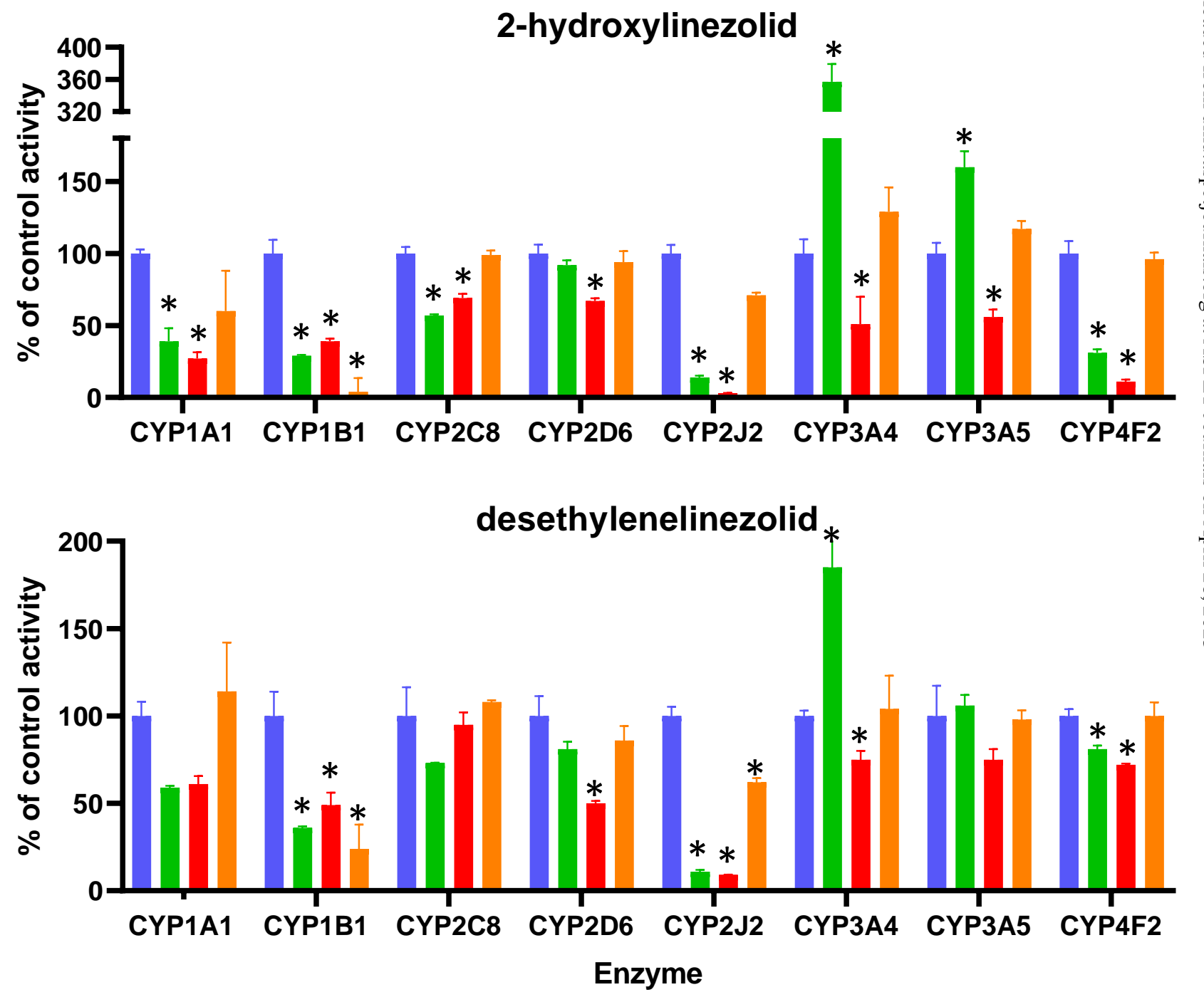

Control LKY-047 sesamin 1-(3-chlorophenyl)-3-phenylurea

Figure 6 
